\title{
A agroindústria canavieira do Paraná pós-desregulamentação: uma abordagem neoschumpeteriana ${ }^{1}$
}

\author{
Darcy Jacob Rissardi Júnior ${ }^{2}$ \\ Pery Francisco Assis Shikida ${ }^{3}$
}

Resumo: O trabalho tem como escopo analisar os principais condicionantes da evolução da agroindústria canavieira paranaense após a desregulamentação setorial, à guisa do instrumental neoschumpeteriano. Deve-se enfatizar o fato de as empresas paranaenses que compõem o setor agroindustrial canavieiro estarem, desde a desregulamentação setorial, ocorrida em 1990, inseridas no paradigma tecnológico vigente no setor, em que importa estar atento a atributos importantes para a maior competitividade setorial, tais como: maior apuração de custos; introdução de inovação em produtos e processos; e aquisição e construção de competências e habilidades no desenvolvimento de capacitações produtivas, tecnológicas e organizacionais. Como resultados a serem ressaltados pode-se citar a razoável capacidade de adaptação às condições de livre concorrência em que se encontraram as agroindús-

\footnotetext{
${ }^{1}$ Os autores são gratos aos pareceristas desta Revista pelas profícuas sugestões e comentários.

${ }^{2}$ Mestre em Desenvolvimento Regional e Agronegócio pela Universidade Estadual do Oeste do Paraná-UNIOESTE (Campus de Toledo). Administrador na Universidade Tecnológica Federal do Paraná - Campus de Medianeira. Avenida Brasil, 4232. CEP 85.884000. Medianeira-PR. darcy@utfpr.edu.br

${ }^{3}$ Professor Associado do Curso de Ciências Econômicas e do Programa de Mestrado em Desenvolvimento Regional e Agronegócio da UNIOESTE (Campus de Toledo). Bolsista de Produtividade em Pesquisa do CNPq e Pesquisador do GEPEC - Grupo de Pesquisa em Agronegócio e Desenvolvimento Regional. Rua da Faculdade, 645. CEP: 85.903-000. Toledo-PR.pfashiki@unioeste.br
} 
trias canavieiras paranaenses no período de 1990 a 2005, investindo em inovações tecnológicas de produtos e processos. Houve, neste aspecto, uma heterogeneidade tecnológica, no qual alguns se distanciam dos demais em função de adoção de estratégias tecnológicas ofensivas. Outros resultados relevantes, em termos de distribuição percentual das respostas das empresas pesquisadas, foram: o grande impacto causado pelas inovações tecnológicas ocorridas na área agrícola e o learning-by-interacting como tipo de aprendizado predominante na agroindústria canavieira paranaense.

Palavras-chave: agroindústria canavieira, referencial neoschumpeteriano, inovação, tecnologia, Paraná.

Classificação JEL: Q12, Q13 e Q16.

Abstract: The study has as aim to analyse the main conditions of the evolution of the Paraná State sugar cane agroindustry after the sectorial deregulation, according to the neoschumpeterian instrument. It must be emphasized the fact that the Parana State companies which compose the sugar cane agro-industrial sector to be inserted, since the sectorial deregulation occured in 1990, in the effective technological paradigm in the sector, where it is necessary to be alert to the important attributes for the biggest sectorial competitiveness, such as: bigger verification of costs; introduction of innovation in products and processes; and acquisition and construction of abilities and skills in the development of productive, technological and organization qualifications. As corollary, the reasonable capacity of adaptation to the conditions of free competition in the Parana State sugar cane agroindustries in the period of 1990 to 2005, investing in technological innovations of products and processes can be stood out. There was, in this way, a technological heterogeneity, where some move away because of the adoption of offensive technological strategies. Other excellent results, in percentile distribution, of the searched companies answers were: the great impact caused by the occured technological innovations in the agricultural area and learning-by-interacting as a type of predominant learning in the Paraná State sugar cane agroindustry. 
Key words: sugar cane agroindustry, neoschumpeterian approach, innovation, technology, Paraná.

JEL Classification: Q12, Q13 e Q16.

\section{Introdução}

Dos anos 70 à virada para o século XXI, profundas mudanças ocorreram no mundo. A rigidez deu lugar à flexibilidade. A globalização rompe as cercas nacionais, acelerando, de uma forma muito forte, as mudanças, e valorizando, de modo definitivo, as relações do homem com o meio ambiente. $\mathrm{O}$ foco do que será a grande abertura dos mercados externos é a lógica evidente, no século XXI, da sinergia entre a agricultura de alimentos e a energética. O inevitável aumento de consumo de alimentos nos países em desenvolvimento levará à necessidade de abertura dos mercados (sobre isto ver: PAULILLO et al., 2006).

O impacto da globalização e a lógica econômica fazem o capital produtivo buscar os nichos mais propícios para seu desenvolvimento, nos quais o Brasil tem dois produtos considerados muito competitivos, como o álcool e o açúcar.

Dentro do processo de agroindustrialização, a canavieira passou por três fases distintas de desempenho, definidas pelo Programa Nacional do Álcool (PROÁLCOOL). A primeira fase (1975 a 1979) foi caracterizada pelo crescimento moderado, na qual prevalecia o modelo subvencionista como padrão de sobrevivência, destacando a produção de álcool anidro (adicionado à gasolina). A segunda fase (1980 a 1985) foi caracterizada pela expansão acelerada, destacando a produção de álcool hidratado (álcool combustível). A terceira fase (1986 a 1995) caracterizou-se pela desaceleração e crise do Programa, na qual o setor passou por um processo de desregulamentação estatal (SHIKIDA, 1998).

O PROÁLCOOL, porém, ainda que tenha exercido um papel determinante na evolução da agroindústria canavieira, não fez com que o Paraná se transformasse numa monocultura da cana, e nem este era o objetivo.

No Paraná a atividade canavieira ocupa, por razões edafoclimáticas, pouco mais de $2 \%$ das terras agricultáveis do estado (com forte incidência 
na faixa norte, especificamente nas mesorregiões Noroeste, Norte-Central, Norte Pioneiro e Centro-Ocidental Paranaense), não impedindo, porém, que o segmento seja um dos principais pilares da economia estadual, proporcionando geração de riqueza a mais de uma centena de municípios e garantindo postos de trabalho para mais de meio milhão de trabalhadores (Associação de Produtores de Álcool e Açúcar do Estado do Paraná - ALCOPAR, 2005).

Diante disto, a intenção deste trabalho é analisar os principais condicionantes da evolução das agroindústrias canavieiras do Paraná após a desregulamentação setorial, à guisa do instrumental neoschumpeteriano.

A utilização da abordagem neoschumpeteriana deve-se ao fato de que esta corrente do pensamento econômico dá como certo, além de outras razões, que existe uma dinâmica competitiva na qual a inovação é um elemento central de diferenciação entre as empresas.

As disparidades na dinâmica industrial geradas pelas características do processo de inovação tecnológica podem ser explicadas recorrendo à literatura neoschumpeteriana. Os neoschumpeterianos, portanto, discorrem sobre questões ligadas à evolução das firmas num sistema capitalista, e que norteará este estudo por meio de conceitos elaborados por alguns de seus expoentes, tais como: paradigmas e trajetórias tecnológicas (DOSI, 1982); estratégias tecnológicas (FREEMAN, 1974); rotinas, seleção e busca de inovações (NELSON e WINTER, 1982); processos de aprendizado (ROSENBERG, 1982); e incertezas e diferenças de comportamento na agricultura (COCHRANE, 1958) ${ }^{4}$.

Este trabalho limitar-se-á ao período pós-desregulamentação, como recorte temporal, e tentará abarcar todas as agroindústrias pertencentes ao setor canavieiro, uma vez que os estudos analisando o comportamento destas firmas no Estado do Paraná após a retirada do governo do setor canavieiro permeiam, na maioria das vezes, estudos bem localizados, ou seja, de uma ou outra organização.

O período a ser tratado reveste-se de grande importância para todos aqueles que compõem o setor pesquisado, pois o Paraná de uma condição

${ }^{4}$ Tendo em vista que algumas dessas perspectivas teóricas foram originalmente formuladas para a indústria de transformação e, secundariamente, para o setor de serviços, os autores desta pesquisa recorreram também aos trabalhos nacionais que analisaram a competitividade do sistema agroindustrial da cana-de-açúcar, como é o caso de Farina e Zylbersztajn (1998), do Grupo Pensa da FEA/USP, e Shikida et al. (2002). 
periférica na cultura da cana-de-açúcar, ocupa hoje a segunda posição no ranking brasileiro em produção dos principais derivados da cana, o açúcar e o álcool, devido, entre outros fatores, ao grande progresso tecnológico.

Para Shikida e Alves (2001), o desenvolvimento tecnológico pelo qual tem passado a agroindústria canavieira paranaense tem refletido em altos rendimentos agrícolas e industriais, ressaltando o bom aproveitamento de subprodutos da cana e o uso adequado de tecnologias agrícolas e mecânicas.

\section{Metodologia}

Isto posto, pode-se estabelecer algumas etapas de trabalho para se chegar à descoberta das questões prioritárias e à ação mais eficaz para transformar a realidade. Chizzotti (2001) relaciona três fases fundamentais para a consecução do trabalho, a saber: a determinação da pesquisa; a definição da pesquisa; e a estratégia de ação.

Deve-se enfatizar que a determinação da pesquisa, bem como a definição do assunto a ser abordado neste trabalho, deve-se, em grande parte, à abertura e contato que as usinas e destilarias do Paraná possuem com a Universidade Estadual do Oeste do Paraná (UNIOESTE), Campus de Toledo, mais precisamente com os pesquisadores do Grupo de Pesquisa em Agronegócio e Desenvolvimento Regional (GEPEC).

Quanto à estratégia de ação, no caso deste trabalho, dividiu-se a pesquisa em duas etapas. A primeira foi a busca, na literatura, dos conceitos-chave da abordagem neoschumpeteriana e, na segunda, as informações foram coletadas in loco por intermédio de pesquisas de campo, que consiste na observação dos fatos tal como ocorrem espontaneamente, com os dados sendo obtidos mediante interrogação com aplicação de questionário auto-aplicado, ou seja, o pesquisado responde de próprio punho.

Trabalhou-se, portanto, com dados oriundos da literatura sobre o objeto em estudo e com os dados coletados por meio do questionário somente como caráter comprobatório das hipóteses levantadas, já que se trata de uma pesquisa qualitativa.

O questionário utilizado nesta pesquisa de campo foi constituído de perguntas fechadas, abertas e combinando os dois tipos, e foi aplicado 
pelo pesquisador por meio de contato direto com o pesquisado, o que possibilitou explicar e abordar os objetivos da pesquisa e esclarecer, em alguns momentos, dúvidas dos respondentes com relação a certas questões. No entanto, alguns questionários foram enviados pelo correio, em face da dificuldade de obtenção durante o período em que a pesquisa foi realizada.

Para a obtenção das respostas foram utilizados como informantes-chave os Diretores-Presidentes destas organizações e, na sua ausência ou impossibilidade de responder ao questionário, deu-se preferência aos cargos de diretoria que estão diretamente subordinados ao Diretor-Presidente, conforme o organograma de cada empresa pesquisada.

\subsection{A técnica de pesquisa}

Esta pesquisa baseia-se em um tipo de amostragem não probabilística, que pode, a fortiori, ser rotulada como amostragem possível.

Para a obtenção dos dados mediante técnica de interrogação, optouse pela aplicação de um questionário, enviado via correio, juntamente com uma carta explicativa aos informantes-chave sobre a pesquisa. $\mathrm{Na}$ construção das questões procurou-se traduzir os objetivos desta pesquisa em quatro blocos de perguntas: informações gerais sobre a empresa; informações sobre fatores potencializadores e limitantes da inovação e efeitos da inovação introduzidas na empresa durante 19902005; descrição técnica da empresa; aprendizado, medidas estratégicas e organizacionais importantes e financiamento da inovação. Este questionário foi composto de 17 grandes indagações, sendo subdividido em 93 perguntas no total.

No mês de julho de 2005 foram enviados questionários (via correio) para todas as unidades produtivas do Paraná (Figura 1), o que resultou no envio de 23 questionários (a base de informação usada para esta finalidade foi a "Relação das unidades produtoras de açúcar e álcool do Estado do Paraná” obtida no site da Associação de Produtores de Álcool e Açúcar do Estado do Paraná - www.alcopar.org.br). Cumpre dizer, contudo, que o universo desta pesquisa são os 23 grupos econômicos que atuam na agroindústria canavieira paranaense. 
Figura 1 - Agroindústria canavieira no Paraná

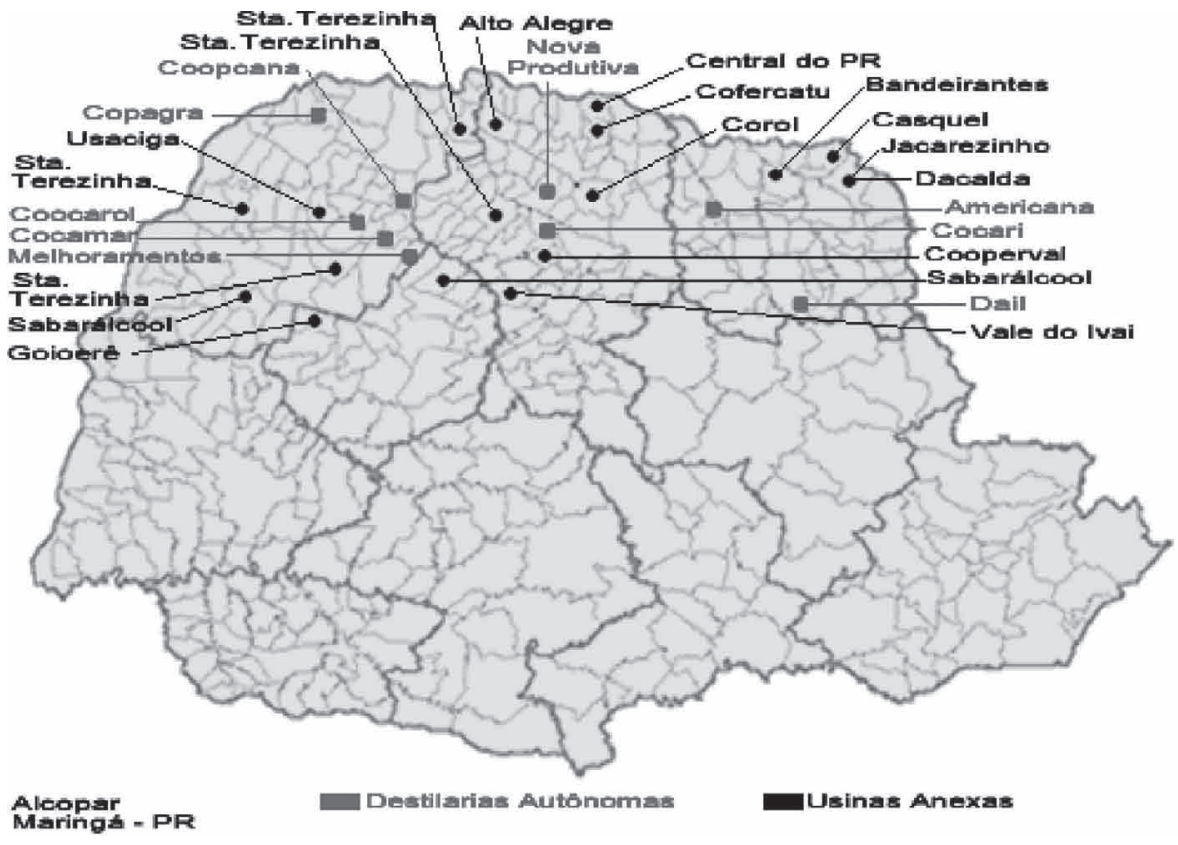

Fonte: ALCOPAR (2004)

O primeiro lote de questionários preenchidos e devolvidos (via correio) foi recebido em julho de 2005 e correspondeu a 34,8\% do número de questionários enviados.

Feitas algumas consultas (via telefone) às usinas e destilarias que não preencheram e, conseqüentemente, não devolveram os questionários, decidiu-se, então, no mês de agosto de 2005, reencaminhar 11 novos questionários (via correio).

Como resultado final, do total de questionários enviados, foram preenchidos e devolvidos 10 questionários, obtendo-se um índice de respostas de 43,5\%. Segundo Gil (2000), para esta técnica de pesquisa (questionário enviado via correio) é considerado satisfatório o índice de 20 ou $25 \%$ de devolução.

Decidiu-se, ainda, nos meses de agosto e setembro de 2005, fazer uma visita a duas unidades produtoras para, entre outros objetivos, proporcionar maiores esclarecimentos sobre a importância e finalidade desta pesquisa. Diante disso, o total de questionários preenchidos e 
devolvidos atingiu um índice final de 56,5\%, valor este considerado satisfatório para os objetivos de presente estudo.

\section{Inovações e tecnologias das firmas paranaenses: resultados e discussões}

A análise, a partir da teoria neoschumpeteriana, para as firmas da agroindústria canavieira paranaense, constitui-se em um importante instrumental para a investigação do processo evolucionário por qual passaram estas agroindústrias pós-desregulamentação setorial.

Dentre os objetivos comumente propostos neste tipo de estudo está a idéia de que a análise de uma determinada fração do universo permitirá que se façam ingerências acerca desse universo. Porém, deve-se ter em mente as limitações que existem quanto à generalização dos resultados obtidos.

Determinados e enfatizados estes aspectos, nesta seção do trabalho faz-se um detalhamento de como foram aplicados os questionários junto às usinas e destilarias da agroindústria canavieira do Paraná, procurandose obter algumas informações como: Quais os processos de aprendizado adotados pelas usinas e destilarias? Ou, quais as estratégias tecnológicas comumente utilizadas por estas agroindústrias? Ou, ainda, quais as relações existentes entre Estado-agroindústria canavieira e P\&D-agroindústria canavieira pós-desregulamentação setorial?

Portanto, a análise desta amostra “possível” (porém, representativa) de usinas e destilarias da agroindústria canavieira paranaense irá constituir-se em um importante auxílio para a investigação da evolução neste setor, complementando, dessa forma, aspectos ressaltados na Seção 3 do presente trabalho.

\subsection{Os resultados obtidos}

Conforme exposto, dos 23 questionários efetivamente enviados aos diretores-presidentes das usinas e destilarias do Paraná, foram respondidos 13 questionários, ou seja, 56,5\% do universo pesquisado e que, em termos de unidades produtoras, controlam 17 unidades no estado. A distribuição percentual dos questionários respondidos, por tipo de unidades produtoras, foi a seguinte: $35,0 \%$ para destilarias autônomas 
(só produzem álcool) e 65,0\% para usinas com destilarias anexas (produzem açúcar e álcool).

Segundo dados fornecidos por Triaca (2005), a representatividade da amostra pesquisada em termos de produção da safra 2004/05 do Estado do Paraná, em números finais, foi a seguinte: produção de cana moída, 64,37\% ; produção de álcool anidro, 57,28\% ; produção de álcool hidratado, 69,54\%; e produção de açúcar, 63,73\%.

\subsubsection{Informações gerais sobre as empresas}

Ao se analisar qual o mercado geográfico mais significativo para as empresas nos produtos açúcar e álcool, percebe-se, no caso do açúcar, uma visão mais voltada à exportação, uma vez que todos (100\%), indicaram o mercado internacional como o mais relevante no caso do açúcar. Deve-se ressaltar que, mesmo o Brasil sendo o maior exportador mundial de açúcar, um maior acesso ao mercado internacional estaria vinculado a condições favoráveis desse mercado, uma vez que o mercado doméstico tende a crescer pouco, observando-se, segundo Bacchi (2004), até mesmo uma estagnação, isto nos últimos anos.

Quanto ao álcool, o mercado que as unidades produtoras mais visam é o mercado nacional (69,0\%). Pode-se afirmar categoricamente os motivos que conduzem a esta afirmação, nos dias atuais, são os carros movidos com motores flex ou bicombustíveis, que utilizam tanto gasolina quanto álcool. Segundo a Federação Nacional da Distribuição de Veículos Automotores (FENABRAVE), em seu balanço semestral de 2005, os automóveis bicombustíveis vêm sendo o grande destaque do segmento de automóveis, saindo de uma participação de 29,34\% em janeiro de 2005 para 51,89\% em junho de 2005, transformando os veículos bicombustíveis em líder de vendas. Porém, observa-se que algumas unidades de produção de álcool, atualmente, vislumbram o mercado internacional como o mais importante $(30,7 \%)$. Isto se verifica numa possível tendência de internacionalização do uso do combustível, que abre oportunidades não só para a exportação de matéria-prima, mas também de tecnologia. Em um cenário de alta dos preços internacionais do petróleo e de crescente preocupação ambiental nos países desenvolvidos, o álcool surge como um expressivo combustível alternativo da atualidade. 
Cumpre dizer que a grande variabilidade dos preços de açúcar e álcool, que está relacionada às condições de oferta e demanda desses produtos, indica que a continuidade do setor agroindustrial canavieiro do Paraná exige que se garanta o acesso de seus produtos a novos mercados.

Em relação ao número de empregados e às áreas em que atuam, as empresas pesquisadas apresentam os seguintes números de empregados: 28.018 trabalhadores na área agrícola, 4.885 trabalhadores na área industrial e 1.418 trabalhadores na área administrativa. Nota-se que, de acordo com as unidades pesquisadas, a maior concentração de empregados encontra-se na área agrícola, representando em torno de $82 \%$ de todo o contingente de empregos nas usinas/destilarias. Este índice evidencia, entre outras coisas, a importância social que esta cadeia produtiva representa para o Paraná.

Como exemplo dessa importância social, pode-se citar que todos os trabalhadores das unidades pesquisadas têm seus contratos de trabalho formalmente registrados, afastando-os da informalidade e garantindo, dessa forma, direitos trabalhistas que, até recentemente, não possuíam, principalmente os trabalhadores envolvidos com o corte da cana (este aspecto suscitou dúvidas por parte deste pesquisador, mas, em verificação in loco, de algumas unidades, tal assertiva foi corroborada).

Constata-se, também, que $77 \%$ das empresas respondentes afirmaram que o número de empregos gerados, no período de 1990 a 2005, evoluiu, conforme o aumento da produção, o que ressalta os números cada vez mais superlativos desta cultura para a economia paranaense.

Feita esta exposição inicial das agroindústrias canavieiras paranaenses quanto a algumas informações gerais sobre as empresas pesquisadas, os próximos tópicos deste trabalho procurarão determinar a evolução ocorrida neste setor, desencadeada após a desregulamentação do setor e motivada, principalmente, pelas inovações e desenvolvimento tecnológico das firmas que compõem o setor canavieiro no Estado do Paraná.

\subsubsection{Informações sobre fatores potencializadores e limitantes da inovação e efeitos da inovação introduzidas na empresa durante 1990-2005}

Para determinar alguns avanços tecnológicos ocorridos na agroindústria canavieira do estado, solicitou-se aos informantes que enu- 
merassem os principais avanços que caracterizaram esse período pós-desregulamentação. Observou-se que houve avanços nas três áreas pré-definidas na pesquisa, ou seja, agrícola, industrial e administrativa, conforme Tabela 1 .

Tabela 1 - Distribuição percentual dos principais avanços tecnológicos do setor canavieiro nas áreas agrícola, industrial e administrativa, segundo as empresas pesquisadas no período 1990 - 2005

\begin{tabular}{llr}
\hline \multicolumn{1}{c}{ Área } & \multicolumn{1}{c}{ Itens e Especificações } & $\%$ \\
\hline \multirow{2}{*}{ Área } & Pesquisa em variedades mais produtivas & (ciclo menor, tipos de solo, melhoramento genético) \\
& Máquinas e equipamentos & 76,92 \\
& (colheita mecanizada e caminhões) & 30,77 \\
& Novas tecnologias (maturadores químicos, cultivo e controle) & 23,08 \\
& Aprimoramento do corte manual (treinamento) & 7,69 \\
\hline Área & Softwares (gestão e controle) & 30,77 \\
Administrativa & Informatização & 23,08 \\
\hline & Automação industrial & 53,85 \\
& Novas tecnologias de produção & 30,77 \\
Área Industrial & Inermentação e aproveitamento de subprodutos) & 15,38 \\
& Investimento em assessorias técnicas & 15,38 \\
& Modernização de equipamentos industriais & (caldeira e acionamentos)
\end{tabular}

FONTE: Dados da Pesquisa

* No Paraná há a predominância de cana própria e advinda de acionistas. A classe dos fornecedores de cana concentra-se em poucas unidades (mais especificamente 2) (SHIKIDA e STADUTO, 2005).

Na área agrícola, o item que mais contribuiu para esta evolução foi a pesquisa em novas variedades de cana-de-açúcar. Os programas de melhoramento genético e manejo varietal da cana, realizados no Paraná, principalmente pela RIDESA, têm sido responsáveis por essa mudança.

A escolha de variedades adaptadas às condições locais proporciona rápido crescimento e ocupação do espaço e exige conhecimentos em relação ao espaçamento e perfilhamento, idade e corte; estágio de maturação, época de colheita, clima ao longo do ciclo, solo e fertilidade, adubação, compactação do solo, irrigação (água ou vinhaça), tratos culturais e fechamento, sanidade dos cultivares, brotação da soqueira, florescimento e chocamento, entre outros (HORII, 2004). 
O que determina a diferença entre o potencial produtivo da cana-deaçúcar em condições ideais, 350 toneladas por hectare, resultado obtido por Oliveira et al. (2001) ${ }^{5}$, e o realizado, em média 110 toneladas, são os fatores ambientais de produção como clima, solo e manejo fitotécnico. E é aí que o manejo varietal pode fazer diferença.

Cumpre dizer que é da exploração das características de cada variedade de cana, a partir da geração de informações locais, do conhecimento das condições do ambiente de produção em cada propriedade que se devem originar os grandes ganhos em produtividade daqui para frente, segundo especialistas (JORNAL PARANÁ AÇÚCAR E ÁLCOOL, 2005).

Atuando num mercado mais competitivo, algumas usinas/destilarias buscaram novos caminhos para garantir a sobrevivência e expansão de seus negócios. Surgiram, então, as estratégias de especialização na produção de açúcar e álcool e no aumento da produtividade das áreas industriais e agrícolas. Essas empresas investiram (algumas ainda se encontram em processo de investimento), além da produção de cana, na automação industrial (uma nítida trajetória tecnológica).

A Tabela 1 apresenta este item como o mais significativo avanço tecnológico da área industrial, com um índice de 53,85\%, segundo as empresas pesquisadas. Para Vian (2003), a automação industrial permitiu uma equalização da produtividade entre as pequenas e médias empresas, de um lado, e as grandes usinas de outro. Outrossim, este tipo de melhoria foi fundamental para o aproveitamento dos subprodutos, entre eles o bagaço, usado para alimentação animal e para a co-geração de energia elétrica, viabilizando novas fontes de renda para as usinas.

As usinas podem ser totalmente automatizadas, utilizando-se desta tecnologia para controlar os processos de cozimento de açúcar,

${ }_{5}^{5}$ Para um melhor entendimento sobre potencial produtivo, ver: Souza França et al. (2004) e Teramoto (2003). Cumpre dizer ainda que a agroindústria canavieira do Paraná possui um bom rendimento agrícola de cana colhida (média de 74 toneladas/hectares), acima da média nacional (que é 72 toneladas/hectares). Outrossim, de acordo com um estudo de caso feito para o Paraná por Ramão et al. (2007, p.21), "em se tratando da relação desempenho/rendimento, cada cortador braçal de cana atingiu, em média, 6,44 toneladas/dia na safra 2005/2006, obtendo um rendimento médio de $\mathrm{R} \$ 24,94$ por dia de trabalho. Considerando o valor do salário mínimo vigente no último semestre de 2006, ou seja, $\mathrm{R} \$ 350,00$, pode-se afirmar que o valor recebido por cada cortador de cana mediano representa cerca de 2,49 salários mínimos por mês, correspondente a R \$ 871,50”. 
as centrífugas, a extração e o tratamento do caldo da cana, a fábrica de levedura, as colunas de destilação de álcool, as caldeiras e a casa de força, sendo estes dois últimos de fundamental importância para a co-geração.

Quanto à área administrativa, o avanço tecnológico mais significativo está relacionado à utilização de softwares, tanto de gestão como de controles, e a informatização. Isto permite, dentre outros benefícios, a transferência de informações, por exemplo, da área agrícola para a administrativa, substituindo com segurança e rapidez os relatórios operacionais, o que facilita a tomada de decisões e permite o controle preciso das operações envolvidas.

Tendo havido, então, avanços relativos nestas áreas supracitadas, nas quais está inserida a maior parte das atividades desenvolvidas deste setor agroindustrial, o presente trabalho procurou determinar, na opinião dos informantes, qual a área que mais impactou a agroindústria canavieira paranaense em termos de avanço tecnológico.

Para $77 \%$ dos entrevistados, a área agrícola foi a mais impactante em termos de inovação. Isto evidencia que a primeira, e talvez principal característica dessa cadeia produtiva - que não pode ser negligenciada, já que interfere na quantidade e qualidade da matéria-prima - é que seu principal insumo, a cana-de-açúcar, é de origem agrícola. Dessa forma, está sujeito aos riscos climáticos, fitossanitários e à sazonalidade da produção, que podem impor fortes impactos sobre a quantidade ofertada e sobre a renda dos produtores e indústria.

As grandes metas de produção e produtividade das unidades industriais são baseadas na qualidade da matéria-prima que, no caso da cana-de-açúcar, representa, segundo Horii (2004), 65\% a 72\% do custo dos produtos finais.

Espera-se que todas as inovações e avanços tecnológicos que ocorrem nos mais diversos setores de uma economia de livre mercado possuam, em algum momento, uma fonte de atualização ou cooperação tecnológica. Sobre estas fontes (Tabela 2), o setor agroindustrial canavieiro do Paraná apresentou como os mais utilizados freqüentemente: os fabricantes de equipamentos (84,62\%); experiência dos técnicos contratados $(84,62 \%)$; publicações técnicas e científicas (76,92\%); e conferências ou reuniões profissionais $(76,92 \%)$. 
Tabela 2 - Distribuição percentual do grau de utilização das fontes de atualização/cooperação tecnológica segundo as empresas pesquisadas no período 1990 - 2005

\begin{tabular}{lcccc}
\hline \multirow{2}{*}{ ITENS } & \multicolumn{4}{c}{ GRAU DE UTILIZAÇÃo } \\
\cline { 2 - 5 } & $\begin{array}{l}\text { Utiliza com } \\
\text { freqüência }\end{array}$ & Raramente & Não utiliza & $\begin{array}{c}\text { Não } \\
\text { respondeu }\end{array}$ \\
\hline Outras Empresas do Grupo & 38,46 & 0 & 61,54 & 0 \\
Publicações técnicas e científicas & 76,92 & 15,38 & 0 & 7,69 \\
Conferências ou reuniões profissionais & 76,92 & 15,38 & 0 & 7,69 \\
Participação em congressos científicos & 38,46 & 53,85 & 0 & 7,69 \\
Feiras ou exposições nacionais e inter- & 38,46 & 53,85 & 0 & 7,69 \\
nacionais & 53,85 & 30,77 & 7,69 & 7,69 \\
Institutos de pesquisa & 61,54 & 38,46 & 0 & 0 \\
Universidades & 46,15 & 38,46 & 7,69 & 7,69 \\
Associações de classe & 69,23 & 30,77 & 0 & 0 \\
Utilização de redes de informação & 53,85 & 23,08 & 15,38 & 7,69 \\
(Internet etc.) & 84,62 & 7,69 & 0 & 7,69 \\
Clientes/consumidores & 69,23 & 30,77 & 0 & 0 \\
Fabricantes de equipamentos & 30,77 & 61,54 & 0 & 7,69 \\
Fornecedores de softwares & 61,54 & 30,77 & 7,69 & 0 \\
Concorrentes & 84,62 & 15,38 & 0 & 0 \\
Firmas de consultoria & & & & \\
Experiência dos técnicos contratados & & & 0 & 0 \\
\hline FONTE: Dados da Pesquisa & & & 0 & 0 \\
\hline
\end{tabular}

FONTE: Dados da Pesquisa

Este resultado mostra, de certa forma, que as empresas paranaenses da agroindústria canavieira procuram minimizar a presença da incerteza, pois, segundo Nelson e Winter (1996), o processo de inovação, ao envolver um alto grau de incerteza, não só antes como também após sua introdução, gera um contínuo desequilíbrio de mercado que pode gerar, para Possas (2004, p. 91), “indeterminações e open ends que inibem não só a otimização estática, mas a própria presunção de ser possível alguma otimização dinâmica”.

Por isso, é preciso aceitar o fato de que, inerente às políticas inovativas e tecnológicas adotadas pelas firmas, em um ambiente de incerteza a previsibilidade é baixa, e a possibilidade de erros é alta. 
De acordo com Dosi (1984), a inovação envolve "solução de problemas”, com vistas simultaneamente a atender a necessidades tanto de mercado quanto de custos. A solução surge do próprio uso de informação obtida (fabricante de equipamentos), experiência prévia (técnicos contratados) e do conhecimento formal (publicações técnicas e científicas e conferências ou reuniões profissionais).

Outra ligação que pode ser feita das respostas obtidas com a teoria neoschumpeteriana é que as empresas buscam suas novas tecnologias dentro de uma categoria que está influenciada pela tecnologia em uso e sua trajetória recente (DOSI et al., 1990).

Uma vez que as novas tecnologias vêm confrontando a maior parte das empresas com a quebra de suas trajetórias anteriores, a necessidade de informação sobre futuros desenvolvimentos tornou-se ainda mais crucial. A participação em arranjos de colaboração tornou-se de fundamental importância para que o processo de inovação ocorra de forma efetiva e particularmente para prover um acesso mais rápido a capacitações tecnológicas que não estejam bem desenvolvidas dentro da empresa.

Quanto ao impacto resultante das inovações, introduzidas no período de 1990 até 2005, nota-se, de acordo com as firmas pesquisadas, maior freqüência das respostas para os efeitos associados aos processos, com destaque para os itens "redução dos custos de trabalho por unidade produzida" e "redução do consumo de energia e materiais por unidade produzida”. Outros itens que conseguiram expressivo realce foram: "melhoria da qualidade de produtos", "melhoria do impacto ambiental ou aspectos associados à segurança” e "cumprimento de regulamento e normas”.

As empresas que obtêm êxito são aquelas nas quais há um adequado balanço entre as inovações no processo e a inovação em produtos. Estes resultados confirmam a alocação de recursos em fontes de obtenção de tecnologia, como forma de, entre outros motivos, criar novos e melhores produtos e processos de produção e, assim, aumentar sua competitividade para não somente se manter no mercado, como também melhorar a capacitação para atingir outros novos. Isto está de acordo com algumas literaturas citadas anteriormente, quais sejam, Shikida et al., (2002) e Vian (2003).

Para finalizar a análise deste tópico do trabalho se tornam oportunas algumas considerações sobre os itens "melhoria do impacto ambiental 
ou aspectos associados à segurança” e "cumprimento de regulamento e normas”, que obtiveram, também, uma importância significativa na opinião das empresas pesquisadas.

A questão ambiental sempre foi o "calcanhar de Aquiles" do setor canavieiro (PINA, 1972). A cana-de-açúcar carregou, por muitos anos, o ônus de ser uma atividade agrícola extremamente degradadora do solo, poluidora do ar e da água, em suma, causadora de grande impacto ambiental. As últimas décadas, entretanto, mudaram a história do setor canavieiro. De acordo com Rossetto (2004), as pesquisas científicas, aliadas aos avanços tecnológicos, a receptividade do setor pelas inovações e os conceitos de desenvolvimento sustentável, estão transformando a cultura canavieira em uma atividade que pode contribuir para a conservação do solo, gerando poucos resíduos e/ou reutilizando-os no processo produtivo (como é o caso do vinhoto, bagaço etc.). ${ }^{6}$

Observa-se que este é o cenário almejado, mas evidentemente degradações ambientais pontuais no setor (voluntárias ou involuntárias), ainda ocorrem (isto também foi motivo de verificação e constatação in loco).

\subsubsection{Descrição técnica das empresas}

Os sistemas de informação nos processos administrativos e de gestão constituem-se, atualmente, em um fator determinante para o crescimento e competitividade das empresas situadas no setor agroindustrial canavieiro. Este trabalho revela que 54\% das empresas pesquisadas possuem bons níveis de controle e relatórios por computador. Estas empresas possuem, também, redes e acesso à informação on-line, utilizando os computadores em rede em quase todas as funções da empresa.

As demais empresas (46\%) possuem sistema e tecnologia integrados, representando o que de melhor existe no mercado e esta infra-estrutura de informática é usada extensivamente para suporte à decisão em todas as áreas da empresa, influenciando o desenvolvimento dos seus fornecedores de tecnologia, principalmente, de processo.

\footnotetext{
${ }^{6}$ Aspectos como os impactos no uso de recursos materiais e no meio ambiente, a sustentabilidade da base de produção agrícola, os impactos da produção em ações comerciais e os impactos socioeconômicos da agroindústria canavieira, são discutidos em Macedo (2005).
} 
De maneira geral, estes sistemas e tecnologia são usados para obter vantagens competitivas sobre os concorrentes. Na perspectiva evolucionária neoschumpeteriana a partir da concorrência, ressaltando a contribuição clássica de Nelson e Winter (1996), o mercado passa a ser tratado como um ambiente de seleção de inovações em sentido amplo, incluindo novas estratégias, rotinas, produtos e tecnologias.

Nesta análise da descrição técnica das empresas paranaenses da agroindústria canavieira, procurou-se classificar qual a situação que melhor descreve a empresa no aspecto de geração e gestão da implementação de inovações em seus processos. Para 84,62 \% das empresas pesquisadas, a informação sobre novas tecnologias de produção, através de processos produtivos, é ativamente procurada e analisada, como forma de apoio à decisão de alterar o processo produtivo.

Partindo da visão original de Schumpeter (1985), cria-se uma ligação entre inovação e a noção de tecnologia como sendo o conhecimento técnico associado à produção de bens e serviços. Portanto, corrobora-se o conceito de inovação como novos produtos, novos processos, a abertura de novos mercados, a descoberta de diferentes fontes de matéria-prima e novas organizações econômicas.

Particularmente no processo de desenvolvimento de produtos, a agroindústria canavieira paranaense convive com os três subgrupos a que se refere Levins e Cochrane (1996). A pesquisa revela (pelo conjunto das 17 grandes indagações do questionário aplicado) que algumas empresas pesquisadas se comportam como early adopters, ou seja, no processo de desenvolvimento de produtos são estabelecidos procedimentos e objetivos, as atividades ocorrem em paralelo e existem técnicas para gerir vários projetos simultâneos e interdependentes. Há um segundo subgrupo, que possui comportamento semelhante aos followers, ou seja, que optam por projetos maiores adotando procedimentos simples no desenvolvimento e organização desses projetos, ou seja, introduzem somente projetos significativos que já foram testados por outras empresas do setor. E há, ainda, um terceiro subgrupo, os laggards, onde não existem procedimentos definidos quanto ao projeto de desenvolvimento de produtos. Os laggards são, em outras palavras, os retardatários no processo de desenvolvimento de produtos.

Dentre as empresas pesquisadas que possuem atividades ligadas ao 
processo de desenvolvimento de produtos, procurou-se, nesta pesquisa, determinar quais os fatores que motivaram a empresa a realizar inovações relacionadas aos produtos.

De acordo com os apontamentos feitos, três fatores, todos situados num grau de importância entre importante e muito importante, foram determinantes para a motivação das empresas em realizar inovações relacionadas aos produtos. São eles: "criação de novos mercados”; “manutenção ou ampliação da participação no mercado”; e "satisfação de demanda dos clientes”.

\subsubsection{Formas de aprendizado, outras medidas estratégicas e organizacionais importantes e financiamento das inovações}

Dentre as várias formas de aprendizado, o interativo (learning-byinteracting) é considerado fundamental para a transmissão de conhecimento - particularmente o tácito - sendo, portanto, central a dinâmica da inovação. Ainda que as empresas permaneçam como centro dos processos de aprendizado e de inovação, estes são influenciados por contextos mais amplos. Em outras palavras, processos de aprendizado e de inovação não ocorrem num "vácuo” institucional.

A Tabela 3 evidencia o learning-by-interacting como o aprendizado predominante na agroindústria canavieira paranaense. Esta afirmação corrobora resultados anteriores, que indicavam a importância de um processo interativo no processo de inovação, realizado com a contribuição de variados agentes econômicos e sociais que possuem diferentes tipos de informações e conhecimentos. Tal ponto vai ao encontro das idéias de Rosenberg (1982 e 2004).

Para Rosenberg (1982 e 2004), as decisões de inovação envolvem um relativo grau de incerteza, sendo que o mercado funciona como uma espécie de fornecedor de feedbacks ao processo de aquisição e construção de competências e habilidades no desenvolvimento de capacitações produtivas, tecnológicas e organizacionais e, por esta razão, talvez, o learningby-interacting tenha grande importância para a dinâmica tecnológica.

Para Martins (2004), o conhecimento produzido pelo aprendizado externo à firma pode localizar "pontos de estrangulamento", maximizando a utilidade do produto pari passu a uma redução de custos. 
Ademais, podem ocorrer casos em que o usuário/fornecedor apresente também um outro processo de fabricação que possa gerar novas competências ao produtor.

Tabela 3 - Distribuição percentual das firmas pesquisadas da agroindústria canavieira paranaense quanto à maneira pela qual a empresa adquire e constrói competências e habilidades no desenvolvimento de capacitações produtivas, tecnológicas e organizacionais - 2005

\begin{tabular}{llc}
\hline \multicolumn{1}{c}{$\begin{array}{c}\text { Formas de } \\
\text { Aprendizado }\end{array}$} & \multicolumn{1}{c}{ Especificações } & $\%$ \\
\hline Learning-by-using & $\begin{array}{l}\text { Através de experiência própria, no processo de comercia- } \\
\text { lização e uso dos produtos (bens e serviços) }\end{array}$ & 15,38 \\
\hline Learning-by-doing & Através de experiência própria, no processo de produção & 23,08 \\
\hline $\begin{array}{l}\text { Learning-by- } \\
\text { interacting }\end{array}$ & $\begin{array}{l}\text { Através da interação com fornecedores de insumos, com- } \\
\text { ponentes e equipamentos, concorrentes, clientes, consul- } \\
\text { tores, universidades, institutos de pesquisa, prestadores } \\
\text { de serviços, agências e laboratórios governamentais }\end{array}$ & 76,92 \\
\hline $\begin{array}{l}\text { Learning-by-sear- } \\
\text { ching }\end{array}$ & $\begin{array}{l}\text { Através de experiência própria, na busca de novas sele- } \\
\text { ções técnicas nas unidades de P\&D internos }\end{array}$ & 23,08 \\
\hline
\end{tabular}

FONTE: Dados da Pesquisa

Nota: A soma das respostas ultrapassa $100 \%$ porque algumas empresas responderam com mais de uma afirmativa.

Não obstante, este dado ressalta um avanço em relação aos trabalhos de Shikida (1998) e Shikida e Alves (2001), que apontaram o learningby-doing como o mais destacado no Paraná. Cumpre dizer, contudo, que muitos dos avanços obtidos no learning-by-interacting derivam do learning-by-doing.

A escolha de estratégia das empresas é marcada pelos recursos de que cada uma dispõe, pela identificação do corpo diretivo com a empresa, pelas características dos meios de financiamento, de inovação e produção que, junto com o tipo de setor, determinam a concorrência. E a estratégia geral da empresa determinará a estratégia tecnológica e de produto. E esta é determinada pelo grau de identificação do corpo diretivo para com ela, assim como pela aversão ao risco que possam ter (LAZONICK e WEST, 1998).

$\mathrm{O}$ resultado da pesquisa mostra que, quanto à situação que melhor 
descreve a empresa em relação à sua estratégia tecnológica, é que as empresas percebem quais são as necessidades tecnológicas em diferentes departamentos ou funções, monitoram tendências e alguns casos têm formado parcerias tecnológicas estratégicas.

Sobre a estratégia adotada pelas agroindústrias canavieiras paranaenses (Tabela 4), verifica-se que as mais visadas são a defensiva e a ofensiva.

Tabela 4 - Distribuição percentual das firmas pesquisadas da agroindústria canavieira paranaense quanto às características relacionadas a estratégias tecnológicas adotadas pela empresa - 2005

\begin{tabular}{|c|c|c|c|}
\hline Estratégia & Especificações & $\%$ & $\begin{array}{c}\text { Total } \\
\%\end{array}$ \\
\hline Ofensiva & $\begin{array}{l}\text { Possui Pesquisa \& Desenvolvimento (P\&D) internos fortes } \\
\text { Intensiva em P\&D (P\&D interno forte) }\end{array}$ & $\begin{array}{l}15,38 \\
30,77\end{array}$ & 46,15 \\
\hline Defensiva & $\begin{array}{l}\text { Avessa ao risco (aperfeiçoam as inovações introduzidas, } \\
\text { sem optar pelo lançamento de um novo produto) } \\
\text { Intensiva em P\&D (P\&D interno forte) } \\
\text { Forte nas áreas de produção e comercialização }\end{array}$ & $\begin{array}{c}0 \\
30,77 \\
46,15\end{array}$ & 76,92 \\
\hline Imitativa & $\begin{array}{l}\text { Possui P\&D interno limitado } \\
\text { Adquire licenças e know how para realizar suas operações }\end{array}$ & $\begin{array}{l}7,69 \\
7,69\end{array}$ & 15,38 \\
\hline Dependente & $\begin{array}{l}\text { Não possui atividade de } \mathrm{P} \& \mathrm{D} \\
\text { Sua atividade é baseada na concorrência, cliente ou mat }\end{array}$ & $\begin{array}{l}15,38 \\
15,38\end{array}$ & 30,76 \\
\hline Oportunista & Limita sua atuação a clientes particulares & 7,69 & 7,69 \\
\hline Tradicional & $\begin{array}{l}\text { Processos de produção não se modificam constantemente } \\
\text { Aceita relações subordinadas de empresas consideradas } \\
\text { mais fortes }\end{array}$ & $\begin{array}{c}38,46 \\
0\end{array}$ & 38,46 \\
\hline
\end{tabular}

FONTE: Dados da Pesquisa

Quanto ao resultado propriamente dito, percebe-se que 76,92\% das respostas se concentraram em características explicativas de empresas que adotam uma estratégia defensiva e $46,15 \%$ para as que utilizam uma estratégia ofensiva.

A estratégia defensiva é intensiva em pesquisa e desenvolvimento, só que neste caso as forças-chave da empresa estão mais na engenharia de produção e na comercialização do que na pesquisa e desenvolvimento. A inovação nesta estratégia se centra em melhoras incrementais e na 
diferenciação de produto, assim como na capacidade de reagir rapidamente ante as mudanças do setor. Esta estratégia é típica dos mercados oligopólicos, caso do setor agroindustrial canavieiro.

Ao se preferir uma estratégia tecnológica ofensiva, a empresa está desenhada para ser a primeira em colocar novos produtos, processos e/ou materiais no mercado e, deste modo, colocar-se em vantagem em relação aos rivais. Esta estratégia está baseada em uma combinação de acesso privilegiado às tecnologias, fortes capacidades internas de pesquisa e desenvolvimento e na exploração rápida de novas possibilidades.

A adoção de uma estratégia tecnológica ofensiva também depende da presença de economias externas, segundo Freeman (1974), na forma de uma infra-estrutura científica e tecnológica altamente desenvolvida da empresa, bem como na capacitação de suas pessoas e clientes, mediante cursos, manuais, normas, documentos, assistência técnica e serviços de consultoria e desenvolvimento de novos equipamentos. A eficiência no fornecimento destes serviços, segundo esse autor, é que proporcionara o êxito ou não da empresa. Como breve comentário, estas informações confirmam resultado obtido na Tabela 2 .

Para Shikida et al. (2002), as estratégias ofensivas são adotadas por empresas mais modernas, ou seja, caracteristicamente intensivas em P\&D e com elevado nível de pesquisa aplicada.

É importante frisar que as características levantadas neste trabalho de pesquisa confirmam parte do estudo elaborado por Shikida e Alves (2001), os quais concluíram que a agroindústria canavieira paranaense apresenta bom desempenho, seja em termos produtivos, seja em termos tecnológicos, direcionando atenção especial para a questão de P\&D e fazendo bom uso das tecnologias, principalmente agrícolas e mecânicas.

Outrossim, em uma economia capitalista marcada pelo desenvolvimento, o crédito e o capital assumem fundamental importância. O crédito é o elemento principal para fornecer poder de compra aos empresários. Na mesma direção, o capital é considerado um fundo de poder aquisitivo cuja função principal é viabilizar as inovações tecnológicas (SCHUMPETER, 1985).

Com o arrefecimento do modelo tradicional de financiamento, no que tange ao setor canavieiro, o crédito para as unidades produtoras passou por várias mudanças quanto às fontes de recursos, tipos de instrumento 
utilizados e mudança nas instituições de crédito (MORAES, 2000).

A pesquisa confirma esta característica para as fontes de recursos utilizados no financiamento das inovações das agroindústrias canavieiras paranaenses. Há elevada $(92,31 \%)$ participação dos recursos próprios no financiamento da inovação. Pode-se afirmar que, neste cenário, as empresas emergentes ou pouco capitalizadas tendem a enfrentar dificuldades ainda maiores para crescer. Porém, conforme os dados da pesquisa também demonstram, há uma participação até significativa de empresas $(61,54 \%)$ que utilizam o financiamento bancário, apesar do custo elevado das operações de empréstimo.

Sobre esta discussão de fontes de recursos de financiamento para a agroindústria canavieira brasileira, vale frisar que este setor foi um dos grandes beneficiários de benesses do Estado, sendo, inclusive, taxado de "péssimo pagador" (RAMOS, 1999; BACHA, 2004). Outrossim, diante da crise fiscal e do ambiente de desregulamentação setorial, as alternativas de financiamento das usinas, seja para inovação ou não, estão escassas.

Considerando-se a importância da cadeia produtiva da cana-deaçúcar em termos de geração de empregos, de renda e de divisas, e o potencial de fornecimento de energia e de contribuição para redução do efeito estufa pela produção e uso do combustível originado da biomassa, deve-se, segundo Moraes (2002, p. 39) “tomar ações para identificar as fontes e formas de financiamento para os investimentos necessários ao desenvolvimento de novos produtos e processos”.

Por meio da análise destes quatros blocos de perguntas, procurou-se enfatizar a dinâmica tecnológica na qual está inserida a agroindústria canavieira paranaense, que diz respeito às empresas que estão se sobressaindo estarem fortemente alicerçadas no atual paradigma tecnológico vigente no setor. Desta forma, remonta-se ao trabalho de Nelson e Winter (1996), que afirmaram que o ambiente concorrencial tende a produzir vencedores e perdedores, onde algumas firmas certamente tirarão maior proveito das oportunidades técnicas do que outras. Quem está fazendo isto na agroindústria canavieira, está diferenciando-se dos demais.

Por fim, esta pesquisa tratou-se de um estudo qualitativo, fundamentado em questionários aplicados, valendo-se, portanto, de dados primários, que são poucos nessa área. Destarte, sugere-se que mais pesquisas 
possam ser implementadas para examinar novas contextualizações em níveis que a amostra das usinas pesquisadas (embora representativa) não possibilitou conclusões.

\section{Considerações finais}

Constatou-se que o setor canavieiro paranaense vive atualmente um momento pleno de oportunidades e grandes perspectivas para o futuro. A pesquisa demonstrou que o segmento apresenta um parque industrial capaz de atender à demanda interna e externa dos principais produtos, açúcar e álcool.

Ainda sobre a capacidade das empresas paranaenses do setor canavieiro, de atender à demanda, pode-se citar como um dado relevante (confirmado pela pesquisa) a importância dada às exportações. O açúcar, por ser uma commodity internacional, teve uma participação destacada nos itens exportados pelo Estado do Paraná, porém percebe-se atualmente um grande número de empresas paranaenses considerando o mercado geográfico internacional para o álcool como estratégico e promissor.

No entanto, alguns problemas devem ser mais bem tratados e equacionados para evitar a penalização de toda a cadeia produtiva. Como exemplo, pode-se citar que o aumento da oferta dos canaviais, através do programa estadual de expansão da atividade, deve estar sintonizado com o aumento da demanda, caso contrário o crescimento antecipado da oferta de cana-de-açúcar pode significar excedentes, com efeitos negativos sobre os preços, o que, segundo Moraes (2004), iniciaria um ciclo de preços baixos, expulsando os menos competitivos do mercado. Outro problema a ser encarado pelas empresas paranaenses refere-se a um novo modelo de gestão. Considerando o número de produtores e as diversidades existentes, a pesquisa revela uma dispersão (às vezes acentuada) nos processos e procedimentos relacionados, especificamente, ao desenvolvimento de produtos e ao conhecimento da posição competitiva e concorrência.

Em relação à geração de empregos e sua evolução desde a desregulamentação do setor, constata-se a relevância da área agrícola no número de empregos gerados, representado em torno de $80 \%$ da força de trabalho das empresas e uma crescente evolução do número de postos de trabalho a que esteve sujeita esta agroindústria no período de 1990 a 2005, 
atribuídos, em grande parte, ao aumento da produção. Faz-se necessário ressaltar, nesta questão da mão-de-obra, que no Paraná, segundo a ALCOPAR (2005), 100\% dos trabalhadores do setor têm carteira assinada, o que arrefece a figura do "gato" nas lavouras do estado.

Quanto à área mais impactante para a agroindústria canavieira do Paraná no que concerne aos avanços tecnológicos implementados neste setor, no período pós-1990, conclui-se que a área agrícola foi a que mais impactou o setor agroindustrial canavieiro do estado. Esses resultados confirmam trabalhos de diversos autores que afirmaram que a primeira característica dessa cadeia produtiva é que seu principal insumo, a canade-açúcar, é de origem agrícola.

Verificada a necessidade de minimizar a presença de incerteza e consideradas as inovações tecnológicas como um processo de aprendizado que, na literatura econômica, se associa a um processo cumulativo através do qual as firmas ampliam seus conhecimentos, aperfeiçoam seus procedimentos de busca e refinam suas habilidades em desenvolver, produzir e comercializar bens e serviços, verifica-se que, nas empresas do Paraná, o tipo de aprendizado predominante é o learning-by-interacting. Através da interação com fornecedores de insumos, componentes e equipamentos, concorrentes, clientes, usuários, consultores, sócios, universidades, institutos de pesquisa, prestadores de serviços tecnológicos, agências e laboratórios governamentais, a agroindústria canavieira do estado cria e constrói competências e habilidades no desenvolvimento de capacitações produtivas, tecnológicas e organizacionais. Cumpre salientar que este tipo de aprendizado requer, per se, o learning-by-doing.

Com relação às estratégias tecnológicas adotadas, fica evidenciado que as estratégias mais visadas são a defensiva (prioritariamente) e a ofensiva (secundariamente). De acordo com este resultado, pode-se concluir que as empresas paranaenses que optam por uma estratégia defensiva se caracterizam por aversão ao risco, embora contem com processos de P\&D interno. De maneira geral não optam pelo lançamento de um novo produto no mercado, e, sim, pelo aperfeiçoamento do aparato técnico-legal às inovações introduzidas. Diante disto, sua preocupação

\footnotetext{
${ }^{7}$ Na terminologia do setor, "gato" é o contratante de mão-de-obra utilizada diariamente nas lavouras de cana, recrutando o pessoal nas cidades e fazendo o transporte até as fazendas.
} 
está no fator concorrencial e institucional do mercado com atenções especiais para as áreas de treinamento e vendas. Aquelas que procuram desenvolver uma estratégia ofensiva caracterizam-se por buscar a liderança técnica e de mercado e são intensivas em investigação. Nota-se, portanto, que o Estado do Paraná é, de certo modo, progressista, mas, em cotejo com outras literaturas - Moraes e Shikida (2002) e Vian (2003) - São Paulo é o referencial nacional do setor.

Diante deste cotejo, verifica-se que, embora o Paraná tenha evoluído positivamente, há, indubitavelmente, campo ainda para ser explorado em termos de avanços tecnológicos que a agroindústria paulista já implementa (mecanização do corte, comercialização e co-geração de energia elétrica etc.).

Last but not least, cumpre dizer que o tema abordado por este estudo nunca se exaure, uma vez que o setor agroindustrial canavieiro sempre apontará para novas interrogações. Se esta pesquisa suscitou novas investigações sobre este importante segmento da economia paranaense, estaremos em sintonia com o próprio referencial teórico neoschumpeteriano, que busca incessantemente novas evidências a partir de investigações empíricas que nunca cessam.

\section{Referências bibliográficas}

ASSOCIAÇÃO DE PRODUTORES DE ÁLCOOL E AÇÚCAR DO ESTADO DO PARANÁ - ALCOPAR. Disponível em: < http://www. alcopar.org. br > . Acesso em: 18 ago. 2004.

ASSOCIAÇÃO DE PRODUTORES DE ÁLCOOL E AÇÚCAR DO ESTADO DO PARANÁ - ALCOPAR. Relatório 2004. Maringá, 2005. Relatório. Impresso.

BACCHI, M. R. P. A variabilidade dos preços do açúcar e do álcool em São Paulo. Visão Agrícola. Piracicaba, n. 1, p. 100-105, jan./jun., 2004.

BACHA, C. J. C. Economia e política agrícola no Brasil. São Paulo: Atlas. 2004, 226p.

CHIZZOTTI, A. Pesquisa em ciências humanas e sociais. 5. ed. São Paulo: Cortez, 2001. 164 p. 
COCHRANE, W. W. Farm prices: myth and reality. Minneapolis: University of Minnesota Press, 1958. 189 p.

DOSI, G. Technical change and industrial transformation: the theory and an application to the semiconductor industry. London: The Macmillan Press Ltd., 1984. 338 p.

DOSI, G. Technological paradigms and technological trajectories: a suggested interpretation of the determinants and directions of technical change. Research Policy, v. 11, n. 3, p. 147-162, Jun. 1982.

DOSI, G.; PAVITT, K.; SOETE, L. The economics of technical change and international trade. Hemel Hempstead: Harvester Wheatsheaf, 1990. 330 p.

FARINA, E. M. M. Q.; ZYLBERSZTAJN, D. Competitividade do agribusiness brasileiro. São Paulo: PENSA/USP; Rio de Janeiro: IPEA. 1998. v. 5. Sistema agroindustrial da cana-de-açúcar, sistema agroindustrial da soja. 139 p. Mimeografado.

FEDERAÇÃO NACIONAL DA DISTRIBUIÇÃO DE VEÍCULOS AUTOMOTORES - FENABRAVE. Semestral da distribuição de veículos automotores do Brasil 2005. Disponível em: < http://www.fenabrave.org.br > . Acesso em: 29 set. 2005.

FREEMAN, C. Innovation and the strategy of the firm. In: FREEMAN, C. The economics of industrial innovation. Harmondsworth: Penguin Books, 1974. p. 225-282.

GIL, A. C. Técnicas de pesquisa em economia e elaboração de monografias. 3. ed. São Paulo: Atlas, 2000. 217 p.

HORII, J. A cana-de-açúcar como matéria-prima. Visão Agrícola, Piracicaba, n. 1, p. 88-93, jan./jun., 2004.

IGLIORI, D. C. Economia dos clusters industriais e desenvolvimento. São Paulo: Iglu, 2001. 147 p.

JORNAL PARANÁ AÇÚCAR E ÁLCOOL. Novas tecnologias. Maringá, ed. 107, mai. 2005. Caderno especial.

LAZONICK, W.; WEST, J. Organizational Integration and competitive 
advantage: explaining strategy and performance in American industry. In: DOSI, G.; TEECE, D.; CHYTRY, J (Orgs.). Technology, organization and competitiveness. London: Oxford University Press, 1998. p. 247-288.

LEVINS, R. A.; COCHRANE, W. W. The treadmill revisited. Land Economics, Madison, v. 72, n. 4, p. 550-553, nov. 1996.

MACEDO, I. de C. (Org.) A energia da cana-de-açúcar: doze estudos sobre a agroindústria da cana-de-açúcar no Brasil e a sua sustentabilidade. São Paulo: Berlendis \& Vertecchia - UNICA, 2005. 237 p.

MARTINS, J. P. Capacidades tecnológicas da Fiasul Indústria de Fios Ltda (Toledo-PR). Toledo, 2004. 98p. Dissertação (Mestrado em Desenvolvimento Regional e Agronegócio), Universidade Estadual do Oeste do Paraná, Toledo, 2004.

MORAES, M. A. F. D. A cadeia produtiva da cana, em mercado desregulamentado. Visão Agrícola. Piracicaba, n. 1, p. 94-99, jan./jun., 2004.

MORAES, M. A. F. D. A desregulamentação do setor sucroalcooleiro do Brasil. Americana: Caminho Editorial, 2000. 238 p.

MORAES, M. A. F. D. Desregulamentação da agroindústria canavieira: novas formas de atuação do Estado e desafios do setor privado. In: MORAES, M. A. F. D.; SHIKIDA, P. F. A. (Orgs.); Agroindústria canavieira no Brasil: evolução, desenvolvimento e desafios. São Paulo: Atlas, 2002. Cap. 1, p. 21-42.

MORAES, M. A. F. D.; SHIKIDA, P. F. A. (Orgs.). Agroindústria canavieira no Brasil: evolução, desenvolvimento e desafios. São Paulo: Atlas, 2002. 368 p.

NELSON, R.; WINTER, S. An evolutionary theory of economic change. Cambridge. Harvard University Press, 1982. 437 p.

NELSON, R.; WINTER, S. An evolutionary theory of economic change. 6. ed. Cambridge. Harvard University Press, 1996. 437 p.

OLIVEIRA, M. W.; BARBOSA, M. H. P.; MURILO C.; ANDRADE, M. B.; MENDES, L. C. Análise quantitativa do crescimento da variedade de canade-açúcar RB 72454. In: ENCONTRO DE BOTÂNICOS DE MG, BA E ES, 23., Viçosa, 2001. Resumos... Viçosa: UFV/SBB, 2001.V. 1, p.89-89. 
PAUliLlO, L. F.; MELLO, F. O. T.; VIAN, C. E. F. Análise da competitividade das cadeias de agroenergia no Brasil. In: BUAINAIN, A. M.; BATALHA, M. O. (Coord.). Análise da competitividade das cadeias agroindustriais brasileiras. São Carlos: DEP-UFSCAR/IE-UNICAMP, fev. 2006. 119 p. (Projeto MAPA/IICA).

PINA, H. A agro-indústria açucareira e sua legislação. Rio de Janeiro: APEC, 1972. $364 \mathrm{p}$.

POSSAS, M. L. Eficiência seletiva: uma perspectiva neo-schumpeteriana evolucionária sobre questões econômicas normativas. Revista de Economia Política, São Paulo, v. 24, n. 1, p. 73-94, jan./mar. 2004.

RAMÃO, F. P.; SCHNEIDER, I. E.; SHIKIDA, P. F. A. Padrão tecnológico no corte de cana-de-açúcar: um estudo de caso no Estado do Paraná. Relatório de pesquisa disciplinar (Programa de Mestrado em Desenvolvimento Regional e Agronegócio, Cadeira: Introdução ao Agronegócio - Toledo, PR), 2007. 28p.

RAMOS, P. Agroindústria canavieira e propriedade fundiária no Brasil. São Paulo: HUCITEC, 1999. 243p.

ROSENBERG, N. Innovation and Economic Growth. OECD, Paris, 2004. Disponível em: < http://www.oecd.org/dataoecd/55/49/342679.02. pdf > . Acesso em: 20 abr. 2005.

ROSENBERG, N. Inside the black box: technology and economics. Cambridge: Cambridge University Press, 1982. 304 p.

ROSSETTO, R. A cultura da cana, da degradação à conservação. Visão Agrícola. Piracicaba, n. 1, p. 80-85, jan./jun., 2004.

SCHUMPETER, J. A. Teoria do desenvolvimento econômico: uma investigação sobre lucros, capital, crédito, juro e o ciclo econômico. São Paulo: Nova Cultural, 1985. 169 p. (Série “Os economistas”).

SHIKIDA, P. F. A. A evolução diferenciada da agroindústria canavieira no Brasil de 1975 a 1995. 1. ed. Cascavel: Edunioeste, 1998. 149 p.

SHIKIDA, P. F. A.; ALVES, L. R. A. Panorama estrutural, dinâmica de crescimento e estratégias tecnológicas da agroindústria canavieira paranaense. Nova Economia. Belo Horizonte, v. 11, n. 2, p. 123-149, dez., 2001. 
SHIKIDA, P. F. A.; NEVES, M. F.; REZENDE, R. A. Notas sobre a dinâmica tecnológica e agroindústria canavieira no Brasil. In: MORAES, M. A. F. D.; SHIKIDA, P. F. A. (Orgs.); Agroindústria canavieira no Brasil: evolução, desenvolvimento e desafios. São Paulo: Atlas, 2002. Cap. 5, p. 120-138. SHIKIDA, P. F. A.; STADUTO, J. A. R. (Org.). Agroindústria canavieira no Paraná: análises, discussões e tendências. Cascavel: Coluna do Saber, 2005. $168 \mathrm{p}$.

SOUZA FRANÇA, A. F.; MELLO, S. Q. S.; ROSA, B.; BORJAS, A. R.; MUNDIM, S. P.; MAGALHÃES, M. R. F.; MATOS, T. R. A.; REIS, J. G. Avaliação do potencial produtivo e das características químico-bromatológicas de nove variedades de cana-de-açúcar irrigada. 2004. Disponível em: < http://www.cipav.org.co/lrrd/lrrd17/01/souz17008. htm > . Acesso em: 27 set. 2005.

TERAMOTO, E. R. Avaliação e aplicação de modelos de estimativa de produção de cana-de-açúcar (Saccharum spp) baseados em parâmetros do solo e do clima. 2003. 96 f..Tese (Doutorado em Agronomia) - Escola Superior de Agricultura Luiz de Queiroz, Universidade de São Paulo, Piracicaba, 2003.

TRIACA, P. P. Dados safra 2004/2005 - Paraná: números finais [mensagem pessoal]. Mensagem recebida por: < darcy@md.cefetpr.br > em 17 ago. 2005.

VIAN, C. E. F. Agroindústria canavieira: estratégias competitivas e modernização. Campinas: Editora Átomo, 2003. 217 p.

Recebido em dezembro de 2005 e revisto em janeiro de 2007 